\title{
Correlation Between Erythrocyte Glutathione Levels and Severity of
} Melasma

\author{
Izazi Hari Purwoko ${ }^{1}$, Nopriyati Nopriyati ${ }^{1}$, Theodorus Theodorus ${ }^{2}$, Dwi Susanti ${ }^{1}$ and Hari \\ Darmawan ${ }^{1, *}$ \\ ${ }^{1}$ Department of Dermatovenereology, Faculty of Medicine, Dr. Mohammad Hoesin General Hospital, Sriwijaya University, Palembang, Indonesia \\ ${ }^{2}$ Department of Biomedical, Faculty of Medicine, Sriwijaya University, Palembang, Indonesia \\ "Corresponding author: Department of Dermatovenereology, Faculty of Medicine Sriwijaya University, Dr. Mohammad Hoesin General Hospital Palembang, Indonesia. Email: \\ dr.haridarmawan@yahoo.com
}

Received 2020 June 16; Revised 2020 July 02; Accepted 2020 July 04.

\begin{abstract}
Background: Melasma is a common acquired disorder of hyperpigmentation, characterized classically by the presence of symmetrical, light-to-dark, muddy-brown macules with borders on the face, especially the forehead, cheeks, upper lip, chin, and nose. Knowledge of an increase in free radicals and decreased antioxidants in patients with melasma led to the belief that oxidative stress is involved in the pathogenesis of melasma. Glutathione (GSH) is an antioxidant that can be used as a parameter to assess the antioxidant-free radical activity in the pathogenesis of melasma.

Objectives: The study aimed to determine the correlation between erythrocyte glutathione levels and the severity of melasma. Methods: A case series study was done from May to July 2018 in the Outpatient Clinic of Dermatology and Venereology Department, Dr. Mohammad Hoesin General Hospital Palembang. Thirty female patients met the inclusion criteria. The independent variable was the erythrocyte glutathione level, and the dependent variable was the melasma severity. The diagnosis was established based on clinical examinations, and the severity was determined by the modified Melasma Area Severity Index (mMASI) score. The correlation between variables was analyzed using Spearman Rho's test $(\mathrm{P}<0.05)$. The data analysis was done with SPSS version 20.0 (SPSS, Inc Chicago, Illinois).

Results: Thirty female patients were diagnosed with melasma. The mean mMASI score was $8.72 \pm 5.14$ (2.0 to 16.9). Most of the participants had mild melasma (46.7\%). The mild group had the highest mean erythrocyte glutathione level ( $4.05 \pm 0.63 \mu \mathrm{mol} / \mathrm{g})$ and the lowest mean erythrocyte glutathione level was in the severe group $(1.79 \pm 0.16 \mu \mathrm{mol} / \mathrm{g})$. There was a very strong negative correlation between erythrocyte glutathione levels and melasma severity $(r=-0.907 ; \mathrm{P}=0.000)$.

Conclusions: There was a very strong negative correlation between erythrocyte glutathione levels and melasma severity.
\end{abstract}

Keywords: Glutathione, Melasma, mMASI

\section{Background}

Melasma is a skin hypermelanosis disorder caused by melanogenesis dysfunction $(1,2)$. The lesions are circumscribed, symmetrical brownish macules, or patches with irregular edges. It typically occurs on sun-exposed areas, especially the face (1-4). In the Southeast Asia regions, melasma accounts for $2.5 \%$ - $4 \%$ of patients seen in dermatology clinics (5).

Melasma is more commonly observed in women of reproductive age $(2,3)$. The severity of melasma can be assessed using the modified Melasma Area Severity Index (mMASI) (6). The mMASI scoring system was validated in 2017 and is a reliable tool to assess the severity of melasma (7). Melasma more frequently affects women. Although generally not harmful, melasma can cause significant emotional impacts on patients, such as feeling bothered, frustrated, embarrassed, and depressed about their skin appearance. The disease also causes them to feel unattractive. Therefore, it is important to properly diagnose and treat the disease to minimize the burden on the quality of life (8).

Ultraviolet radiation is generally believed to be the main precipitating factor for melasma, which is indicated by the location of the lesions that are most common in sun-exposed areas (9). Chronic exposure to UV radiation increases the production of Reactive Oxygen Species (ROS) and oxidative stress $(10,11)$. The amount of oxidative stress can be assessed through the measurement of molecular biomarkers, one of which is blood glutathione levels (12). 
Glutathione also has anti-melanogenic effects through the inhibition of the tyrosine enzyme and convert of the eumelanin to pheomelanin (13). The predominant form of glutathione in the blood is GSH, and it is mostly found inside erythrocytes (14). The erythrocyte GSH level can be used as a valid oxidative stress biomarker (15).

\section{Objectives}

This study aimed to determine the correlation between erythrocyte glutathione levels and the severity of melasma.

\section{Methods}

A case series study was done from May to July 2018 in the Outpatient Clinic of Dermatology and Venereology Department, Dr. Mohammad Hoesin General Hospital Palembang. During the study period, 30 female patients met the inclusion criteria. The study protocol was approved by the Ethics Committee, Faculty of Medicine, Sriwijaya University.

The study used a consecutive sampling method, with a sample of melasma patients visiting the outpatient clinic during the study period. The severity of melasma was assessed based on the mMASI score. The assessment was done by researchers and supervised by board-certified dermato-venereologists.

Blood specimens were collected at the Prodia Clinical Laboratory. The erythrocyte GSH level was measured using Bioxytech GSH-420 ${ }^{\circledR}$ reagent and EZ Read $2000^{\circledR}$ microplate reader with the quantitative colorimetry method.

The frequency and distribution of data were analyzed with univariate analysis and presented in the form of tables and graphs. The correlation between erythrocyte glutathione levels and the severity of melasma was tested using Spearman Rho's test. The data analysis was performed using SPSS version 22.0.

\section{Results}

This study included 30 female patients with melasma who visited the Dermatology and Venereology DV clinic during the study period from May to July 2018.

Table 1 shows that the mean age of the subjects was $47.10 \pm 8.16$ years (range 29 to 56 years), with the majority of the patients being in the age group of 46 - 55 years (60\%). Most participants had bachelor degrees (56.7\%), with the majority being government employees.

The mean mMASI score was $8.72 \pm 5.14$, with a range of 2.0 to 16.9. The distribution of melasma severity was

\begin{tabular}{|c|c|}
\hline Characteristics & No. (\%) \\
\hline \multicolumn{2}{|l|}{ Age, y } \\
\hline Mean \pm SD & $47.10 \pm 8.16$ \\
\hline Median (min - max) & $49.5(29-56)$ \\
\hline \multicolumn{2}{|l|}{ Age, $y$} \\
\hline $26-35$ & $4(13.3)$ \\
\hline $36-45$ & $6(20.0)$ \\
\hline $46-55$ & $18(60.0)$ \\
\hline $56-65$ & $2(6.7)$ \\
\hline \multicolumn{2}{|l|}{ Education level } \\
\hline No schooling & $1(3.3)$ \\
\hline Junior high school & $1(3.3)$ \\
\hline Senior high school & $11(36.7)$ \\
\hline Bachelor degree & $17(56.7)$ \\
\hline \multicolumn{2}{|l|}{ Occupation } \\
\hline Unemployed & $6(20.0)$ \\
\hline Government employees & $20(66.7)$ \\
\hline Daily workers & $4(13.3)$ \\
\hline
\end{tabular}

mild (46.7\%), moderate (33.3\%), and severe (20\%). The most frequently encountered melasma pattern was centrofacial (56.7\%), mostly distributed in the epidermal type (40\%). All study participants did not report sunscreen use, and 60\% of respondents had a family history of melasma. Data on the distribution of clinical characteristics are shown in Table 2 .

The mean erythrocyte GSH level was $3.13 \pm 1.05 \mu \mathrm{mol} / \mathrm{g}$, with a minimum value of $1.57 \mu \mathrm{mol} / \mathrm{g}$ and a maximum value of $5.40 \mu \mathrm{mol} / \mathrm{g}$. The highest level of erythrocyte GSH was found in the age group of 35 - 45 years, which was $4.12 \pm$ $1.09 \mu \mathrm{mol} / \mathrm{g}$. The lowest was found in the age group of 46 55 years, which was $2.81 \pm 0.99 \mu \mathrm{mol} / \mathrm{g}$ (Table 3 ). The mean erythrocyte GSH levels in the mild, moderate, and severe melasma groups were $4.05 \pm 0.63,2.63 \pm 0.43$, and $1.79 \pm$ $0.16 \mu \mathrm{mol} / \mathrm{g}$, respectively.

There was a negative correlation between GSH levels and age $(\mathrm{r}=-0.331 ; \mathrm{P}=0.074 ; \mathrm{n}=30)$. However, the correlation did not reach statistical significance. The analysis showed that older participants were found to have lower GSH levels, but the difference was not statistically significant. The R2 value of 0.099 indicated that age explained 9.9\% of the variance in the GSH levels (Figure 1).

In addition, there was a significant negative correlation between erythrocyte GSH levels and mMASI score $(r=$ $0.963 ; \mathrm{P}=0.000 ; \mathrm{n}=30$ ), which indicated that the lower the erythrocyte GSH level, the higher the mMASI score. The R2 


\begin{tabular}{|c|c|}
\hline Characteristics & No. (\%) \\
\hline \multicolumn{2}{|l|}{ mMASI score } \\
\hline Mean $\pm S D$ & $8.72 \pm 5.14$ \\
\hline Median (min-max) & $8.1(2.0-16.9)$ \\
\hline \multicolumn{2}{|l|}{ Melasma degree } \\
\hline Mild & $14(46.7)$ \\
\hline Moderate & $10(33.3)$ \\
\hline Severe & $6(20.0)$ \\
\hline \multicolumn{2}{|l|}{ Melasma pattern } \\
\hline Centrofacial & $17(56.7)$ \\
\hline Malar & $10(33.3)$ \\
\hline Mandibular & $3(10.0)$ \\
\hline \multicolumn{2}{|l|}{ Type of Melasma } \\
\hline Epidermal & $13(43.3)$ \\
\hline Dermal & $6(20.0)$ \\
\hline Mixed & $11(36.7)$ \\
\hline \multicolumn{2}{|l|}{ Sunscreen usage } \\
\hline Yes & $0(0)$ \\
\hline No & $30(100)$ \\
\hline \multicolumn{2}{|l|}{ Family history of Melasma } \\
\hline Yes & $18(60.0)$ \\
\hline No & $12(40.0)$ \\
\hline \multicolumn{2}{|l|}{ Erythrocyte GSH level } \\
\hline Mean \pm SD & $3.13 \pm 1.05$ \\
\hline Median (min - max) & $2.94(1.57-5.40)$ \\
\hline
\end{tabular}

\begin{tabular}{lcc}
\hline Table 3. Erythrocyte Glutathione Levels & \\
\hline Age & Total $(\mathbf{N}=\mathbf{3 0})$ & Mean \pm SD \\
\hline $\mathbf{2 6}$ - 35 & 4 & $3.29 \pm 0.91$ \\
\hline $\mathbf{3 6}$ - $\mathbf{5 5}$ & 6 & $4.12 \pm 1.09$ \\
\hline $\mathbf{4 6}$ - 55 & 18 & $2.81 \pm 0.99$ \\
\hline $\mathbf{5 6}-\mathbf{6 5}$ & 2 & $3.13 \pm 0.68$ \\
\hline Mild & 14 & $4.05 \pm 0.63$ \\
\hline Moderate & 10 & $2.63 \pm 0.43$ \\
\hline Severe & 6 & $1.79 \pm 0.16$ \\
\hline
\end{tabular}

value was 0.868 , which indicated that the erythrocyte GSH level explained $86.8 \%$ of the variance in the MMASI score (Figure 2).

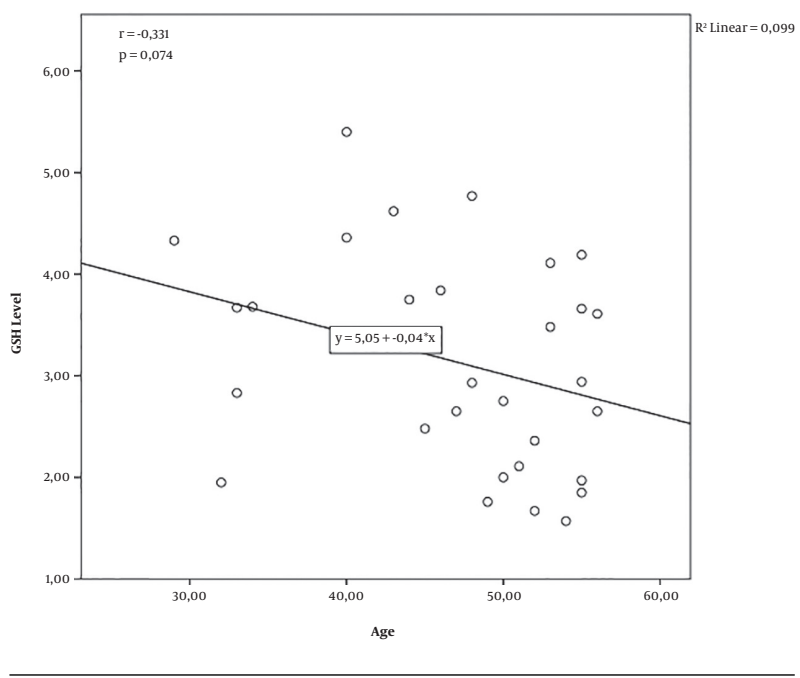

Figure 1. Correlation between erythrocyte glutathione levels and age

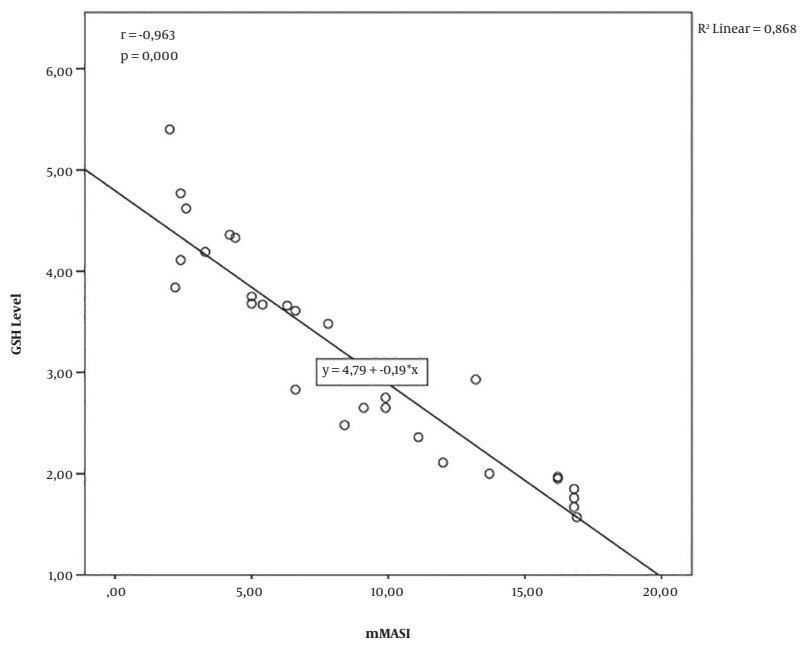

Figure 2. Correlation between erythrocyte glutathione levels and modified melasma area severity index (mMASI)

\section{Discussion}

In this study, 30 melasma patients who met the inclusion criteria were assessed. The mMASI scores and erythrocyte glutathione levels in venous blood were determined for the participants. This study only included female patients because more than $90 \%$ of melasma patients are female (3). From 2013 to 2017, there were 240 visits by melasma patients in the DV clinic of Dr. Muhammad Hoesin Hospital, with a ratio of female to male of 27:1 (16). Epidemiological research in the Department of Dermatology and Venereology Clinic at Dr. Cipto Mangunkusumo Hospital, Jakarta, in 2004 reported that the gender distri- 
bution of melasma patients was $97.93 \%$ females to $2.07 \%$ males (17). Epidemiological studies by Hexel et al. of 953 melasma patients in Brazil obtained a ratio of female to male melasma patients of 39:1 (18).

The greater female ratio in melasma patients is explained by the influence of female sex hormones (estrogen and/or progesterone) in the pathogenesis of melasma. Several studies report that estrogen increases the expression of Trp-1, Trp-2, and tyrosinase activity in human melanocyte culture. Estrogen has shown to increase melanin synthesis in healthy human melanocytes by activating the cAMP protein kinase (PKA) pathway and upregulation of tyrosinase expression and Microopthalmiaassociated Transcription Factor (MITF) (19).

In this study, the mean age of the melasma patients was $47.10 \pm 8.16$ years, with a range of 29 to 56 years, mostly in the age group of 46 - 55 years (60\%). The results of this study are supported by the study by Zainuddin et al., which found that the majority of the melasma patients in Makassar were over the age of $40(76.2 \%)(20)$. Other studies found similar results. Epidemiological studies by Goh and Dlova of 205 melasma patients in Singapore discovered a mean age of 42.3 years for melasma patients (2). A cross-sectional study conducted by Ortonne et al. at nine clinics across several countries found that the mean age of melasma patients was $45.0 \pm 10.7$ in the United States, $41.0 \pm 7.46$ in France, $35.1 \pm 7.18$ in Germany, $40.7 \pm 8.86$ in the Netherlands, $39.5 \pm 7.77$ in Mexico, $41.3 \pm 5.91$ in Italy, $48.7 \pm 6.71$ in Singapore, $37.5 \pm 9.33$ in South Korea, and $48.7 \pm 7.83$ in Hong Kong, almost all of which are above the age of 40 (21).

The most frequently encountered melasma distribution pattern in this study was centrofacial (56.7\%), which corresponds to literature and previous studies, indicating the centrofacial distribution of most melasma lesions (3). Tamega et al.'s study stated the same theory, by reporting a rate of $69.2 \%$ (22). Achar and Rathi's studies reported that the most widespread melasma distribution was centrofacial (55.4\%) (22). Research by Guinot et al. on 197 melasma patients in Tunisia also found that $76 \%$ of melasma patients experienced a centrofacial distribution pattern (23).

In this study, the type of melasma was assessed with a Wood lamp examination (UV light wavelength 340 - 400 $\mathrm{nm}$ ) and dermoscopic examination. The Wood lamp determines the type of melasma by assessing the depth of melanin deposits in the skin (24). The most frequent type of melasma was the epidermal type (43.3\%), which was in line with Zainuddin et al.'s study (78.6\%) (21). A cross-sectional study in 2016 by Jagannathan et al. on 100 melasma patients in India also found the same results (47\%) (24). On theory, during a dermoscopic examination, the epidermal type shows an image of regular brown pigment tissue. The dermal type shows irregular color pig- ments and blue-gray color. In mixed-type melasma, there are both features of the epidermal and dermal types (24).

From this study, it can be concluded that there is an inverse relationship between erythrocyte glutathione levels and the severity of melasma in melasma patients. The lower the erythrocyte glutathione level, the more the patient's melasma severity. Since the decrease in glutathione levels can be caused by oxidative stress, it can also be concluded that an increase in oxidative stress would aggravate the severity of melasma. This is also supported by a study by Seckin et al., which found that oxidative stress, which was proven by the disrupted balance between oxidants and antioxidants, was significantly correlated with the incidence of melasma (10) However, the study did not compare the degrees of the disease.

A decrease in glutathione can cause increased hydroxylation of tyrosinase to dopaquinone, decreased speed of reaction of dopaquinone with thiol, and decreased level of thiol-dopa conjugates. These reactions cause dopaquinone to release and increase the synthesis of eumelanin in the process of melanogenesis. A reduction in glutathione also results in the accumulation of $\mathrm{H}_{2} \mathrm{O}_{2}$, which causes lipid peroxidation, increases tyrosinase activity, and further stimulates the melanin synthesis process (13). On the other hand, glutathione, as a strong antioxidant, is used for the treatment of melasma because of its antimelanogenic properties. The most popular routes of administration are oral, topical, and intravenous, which may be initiated for 10 weeks. Some adverse effects of glutathione administration are cutaneous rash (from a mild rash to fatal Steven-Johnson syndrome or toxic epidermal necrolysis), severe abdominal pain, thyroid, liver, or kidney dysfunction, or some lethal complications such as air embolism, blood-borne infections, and potentially fatal sepsis (25). Therefore, although promising, its usage is to be done with caution for the patient's safety.

\subsection{Conclusion}

Based on the results of the analysis and discussion in this study, it can be concluded that the majority of the melasma patients (46.7\%) experienced mild disease with a mean erythrocyte GSH level of $3.131 \pm 1.053 \mu \mathrm{mol} / \mathrm{g}$. There is an inverse relationship between erythrocyte glutathione levels and the severity of melasma. The lower the level of erythrocyte glutathione, the more the melasma severity.

\section{Footnotes}

Authors' Contribution: Study concept and design: IHP and N. Acquisition of data: IHP and T. Analysis and interpretation of data: DS and HD. Drafting of the manuscript: 
DS and HD. Critical revision of the manuscript for important intellectual content: IHP and N. Statistical analysis: T. Administrative, technical, and material support: DS. Study supervision: IHP.

\section{Conflict of Interests: No conflict of interest is reported.}

Ethical Approval: Certificate No. 167/kepkrsmhfkunsri/2018.

\section{Funding/Support: No funding/support is reported.}

\section{References}

1. Lapeere H, Boone B, Schepper SD, Verhaeghe E, Gele MV, Ongenae K. Hypomelanoses and hypermelanoses. In: Wolff K, Goldsmith LA, Katz SI, Gilchrest BA, Paller AS, Lefel DJ, editors. Fitzpatrick's Dermatology in General Medicine. 8th ed. New York: McGraw Hill; 2012. p. 804-26.

2. Handel AC, Miot LD, Miot HA. Melasma: a clinical and epidemiological review. An Bras Dermatol. 2014;89(5):771-82. doi: 10.1590/abd18064841.20143063. [PubMed: 25184917]. [PubMed Central: PMC4155956].

3. Chang MW. Disorders of hyperpigmentation. In: Bolognia JL, Jorizzo JL, Schaffer JV, editors. Dermatology. 3rd ed. Philadelphia: Elseveier Saunders; 2012. p. 1049-74.

4. Geel NV, Speeckaert K. Acquired pigmentary disorders. In: Griffiths C, Barker J, Bleiker T, Chalmers R, Cramer D, editors. Rook's Textbook of Dermatology. 9th ed. London: John Wiley \& Sons; 2012. p. 1-56.

5. D'Souza P, Rathi S. Epidemiology of Melasma. In: Lahiri K, Charttejee CM, Sarkar R, editors. Pigmentary Disorders: A Comprehensive Compendium. New Delhi: Jaypee Brother Medical; 2014. p. 282-6. doi 10.5005/jp/books/12080_33.

6. Pandya AG, Hynan LS, Bhore R, Riley FC, Guevara IL, Grimes P, et al. Reliability assessment and validation of the Melasma Area and Severity Index (MASI) and a new modified MASI scoring method. J Am Acad Dermatol. 2011;64(1):78-83. 83 e1-2. doi: 10.1016/j.jaad.2009.10.051. [PubMed: 20398960].

7. Abou-Taleb DA, Ibrahim AK, Youssef EM, Moubasher AE. Reliability, Validity, and Sensitivity to Change Overtime of the Modified Melasma Area and Severity Index Score. Dermatol Surg. 2017;43(2):210-7. doi: 10.1097/DSS.0000000000000974. [PubMed: 27930379].

8. Ikino JK, Nunes DH, Silva VP, Frode TS, Sens MM. Melasma and assessment of the quality of life in Brazilian women. An Bras Dermatol. 2015;90(2):196-200. doi:10.1590/abd1806-4841.20152771. [PubMed: 25830989]. [PubMed Central: PMC4371668].

9. Lee AY. Recent progress in melasma pathogenesis. Pigment Cell Melanoma Res. 2015;28(6):648-60. doi: 10.1111/pcmr.12404. [PubMed: 26230865].

10. Seckin HY, Kalkan G, Bas Y, Akbas A, Onder Y, Ozyurt H, et al Oxidative stress status in patients with melasma. Cutan Ocul Toxicol. 2014;33(3):212-7. doi: 10.3109/15569527.2013.834496. [PubMed: 24147944].

11. Choubey V, Sarkar R, Garg V, Kaushik S, Ghunawat S, Sonthalia S. Role of oxidative stress in melasma: a prospective study on serum and blood markers of oxidative stress in melasma patients. Int J Dermatol. 2017;56(9):939-43. doi: 10.1111/ijd.13695. [PubMed: 28681382].
12. Beaulieu M, Costantini D. Biomarkers of oxidative status: missing tools in conservation physiology. Conserv Physiol. 2014;2(1):cou014. doi: 10.1093/conphys/cou014. [PubMed: 27293635]. [PubMed Central: PMC4806730].

13. Villarama CD, Maibach HI. Glutathione as a depigmenting agent: an overview. Int J Cosmet Sci. 2005;27(3):147-53. doi: 10.1111/j.14672494.2005.00235.x. [PubMed: 18492181].

14. Richie JJ, Nichenametla S, Neidig W, Calcagnotto A, Haley JS, Schell TD, et al. Randomized controlled trial of oral glutathione supplementation on body stores of glutathione. Eur J Nutr. 2015;54(2):251-63. doi: 10.1007/s00394-014-0706-z. [PubMed: 24791752].

15. Nikolaidis MG, Kyparos A, Dipla K, Zafeiridis A, Sambanis M, Grivas GV et al. Exercise as a model to study redox homeostasis in blood: the effect of protocol and sampling point. Biomarkers. 2012;17(1):28-35. doi: 10.3109/1354750X.2011.635805. [PubMed: 22288504].

16. Febrianti T, Sudharmono A, Rata IGAK, Bernadette I. Epidemiologi melasma di poliklinik departemen ilmu kesehatan kulit dan kelamin RS. Dr. Cipto mangunkusumo Jakarta Tahun. Perdoski. 2004;33(1):13-7.

17. Neupane DP, Majhi S, Chandra L, Rijal S, Baral N. Erythrocyte glutathione status in human visceral leishmaniasis. Indian JClin Biochem. 2008;23(1):95-7. doi: 10.1007/s12291-008-0023-5. [PubMed: 23105731]. [PubMed Central: PMC3453669].

18. Sheth VM, Pandya AG. Melasma: a comprehensive update: part I. J Am Acad Dermatol. 2011;65(4):689-97. doi: 10.1016/j.jaad.2010.12.046. [PubMed: 21920241].

19. Hexsel D, Lacerda DA, Cavalcante AS, Machado Filho CA, Kalil CL, Ayres EL, et al. Epidemiology of melasma in Brazilian patients: a multicenter study. Int J Dermatol. 2014;53(4):440-4. doi: 10.1111/j.13654632.2012.05748.x. [PubMed: 23967822].

20. Zainuddin F, Irawan A, Djawad K, Seweng A, Sjahril R, Adriani A. The Correlation Between Malondialdehyde Serum Levels and the Duration of Sun Exposure; and Melasma Area and Severity Index in Patients with Melasma in Makassar. Am J Clin Exp Med. 2016;4(3). doi: 10.11648/j.ajcem.20160403.16.

21. Tamega Ade A, Miot LD, Bonfietti C, Gige TC, Marques ME, Miot HA. Clinical patterns and epidemiological characteristics of facial melasma in Brazilian women. J Eur Acad Dermatol Venereol. 2013;27(2):151-6. doi: 10.1111/j.1468-3083.2011.04430.x. [PubMed: 22212073].

22. Leeyaphan C, Wanitphakdeedecha R, Manuskiatti W, Kulthanan K. Measuring melasma patients' quality of life using willingness to pay and time trade-off methods in Thai population. BMC Dermatol. 2011;11:16. doi: 10.1186/1471-5945-11-16. [PubMed: 22182399]. [PubMed Central: PMC3280162].

23. Passeron T, Ortonne J. Pigmentation: dyschromia. In: Baran $\mathrm{R}$, Maibach $\mathrm{H}$, editors. Textbook of Cosmetic Dermatology. 4th ed. Newyork: Informa Healthcare; 2010. p. 311-29. doi: $10.3109 / 9781841847641.037$.

24. Jagannathan M, Sadagopan K, Ekkarakudy J, Anandan H. Clinicoepidemiological Study of Patients with Melasma in a Tertiary Care Hospital-A Prospective Study. Int J Sci Stud. 2017;4:117-20.

25. Sonthalia S, Jha AK, Lallas A, Jain G, Jakhar D. Glutathione for skin lightening: a regnant myth or evidence-based verity? Dermatol Pract Concept. 2018;8(1):15-21. doi: 10.5826/dpc.0801a04. [PubMed: 29445569]. [PubMed Central: PMC5808366]. 